\title{
ARAUCO, MATRIZ RETÓRICA DE CHILE: SÍMBOLOS, ETNIA Y NACIÓN ${ }^{*}$
}

\author{
Arauco, rhetorical origin of Chile: Symbols, race and Nation
}

Armando Cartes Montory ${ }^{* *}$

Recibido: 5 de mayo de 2013. Aceptado: 20 de octubre de 2013.

\section{RESUMEN}

Durante los años de las independencias americanas, los nuevos republicanos debieron buscar elementos que les diferenciaran de Europa, confiriéndoles, al mismo tiempo, una identidad propia. La religión católica o el rechazo al legado hispano, que eran comunes a todos, no bastaban a este propósito. Se recurrió al pasado "heroico" de los habitantes nativos de los territorios y su resistencia a la conquista como fuente de legitimación, en discursos, símbolos y emblemas. A la vuelta de pocos años, en virtud de varios procesos, se abandona el recurso al pasado indígena. Los elementos étnicos permanecen, sin embargo, subyacentes a los símbolos nacionales actuales. Recuperar su sentido y significado permite poner en valor su importancia en la conformación original de la nación chilena y contribuye a los debates actuales sobre la configuración de un Estado plurinacional en Chile.

PALABRAS CLAVES: Símbolos, etnia, nación.

\begin{abstract}
During the years of the American independencies, the recently created Republicans had to search for elements that could distinguish them from Europe, but that would grant them, at the same time, an identity of their own. Catholic religion or the rejection of the

Este artículo forma parte de la tesis para optar al grado de doctor: “Un gobierno de los pueblos...Las provincias en la Independencia de Chile”. Programa de Doctorado en Historia, Universidad Católica de Valparaíso. Director de Tesis, Dr. Eduardo Cavieres Figueroa.

** Universidad de Concepción, carrera de Ciencias Políticas y Administrativas. Correo electrónico: acartes@udec. cl.
\end{abstract}


Spanish legacy, common to all new countries, did not satisfy this purpose. Therefore, in discourse, symbols or anthems, the "heroic" past of the native inhabitants was invoked. Within a few years, as a result of several processes, they abandoned their use of Chile's indigenous past. However, ethnic elements remain underlying the current national symbols. To recover and properly comprehend their value and meaning in the original configuration of the Chilean "nation" contributes to the current debates on the possibility of a plurinational State in Chile.

KEYWORDS: Symbols, ethnic, nation.

\section{INTRODUCCIÓN}

En los albores de la República, la Araucanía representaba un espacio de frontera, donde coexistían mapuches e hispanocriollos, en un proceso de creciente mestización. Cuando llega 1810, la frontera se resiste a los cambios, por temor a perder la autonomía negociada con los españoles y los beneficios que se reportaban de los circuitos comerciales establecidos. Tardará varias décadas en incorporarse plenamente a la República.

Los líderes patriotas del proceso de independencia buscan legitimar el cambio de régimen apartándose de la tradición española. La uniformidad del idioma español y la religión católica dificulta, a su vez, el proceso de construcción de una identidad nacional diferenciada de las naciones vecinas, basada en estos elementos. De ahí que el recurso a los héroes épicos de la resistencia indígena contra la conquista española, en tiempos pretéritos, resulta funcional al proyecto nacional. En los discursos, los emblemas y los símbolos aparece, entonces, la figura de los guerreros de La araucana.

La llamada frontera influyó muy fuertemente el proceso de configuración de la nación. No se comprende el proceso de independencia sin la participación de los indígenas, en los símbolos, los combates y la configuración discursiva del nuevo Estado. Las cuestiones de nacionalidad, ciudadanía y territorio de la República en ciernes están atravesadas por estos debates. Finalmente, acabarán como una cuestión pendiente, que se renuncia a resolver por unas décadas y nunca lo será totalmente. Parece necesario, en consecuencia, mirar la independencia desde allende el Biobío, con un triple objetivo: observar cómo la Araucanía influyó política, militar y discursivamente en la conformación republicana; la manera en que sus habitantes percibieron los sucesos y participaron en ellos; $y$, finalmente, de qué modo estos transformaron el espacio fronterizo. En esa mirada, los símbolos y emblemas aportan elementos iluminadores. 
Con los años, se diluye el recurso a lo indígena, a medida que la República y la nación construyen su propio panteón. Subsisten, no obstante, en diversos elementos de los emblemas patrios los símbolos de la matriz indígena de nuestra nacionalidad. La configuración simbólica del imaginario patrio, en una mirada contemporánea, requiere del rescate de la presencia y el sentido de estos componentes gráficos de la identidad mestiza de Chile.

\section{EL MUNDO ALLENDE EL BIOBÍO}

Al sur del Biobío se extendía una vasta región, cuya evolución, a lo largo de los siglos coloniales, le había dado características propias. Superado el primer siglo de guerra feroz, luego de la gran sublevación de 1654, las cosas empezaron a cambiar. Por un lado, comienza a asumirse la imposibilidad de someter a la región con las pocas fuerzas que conformaban las huestes hispanas. La extensa región que se prolongaba naturalmente hasta el Reloncaví, cubierta en parte por selvas impenetrables, albergaba una población no inferior a 200.000 personas $^{1}$, demasiada para el ejército hispanocriollo, distribuido en precarios fuertes y pueblos a lo largo de la Frontera. Por otra parte, el eje de la economía del reino se desplazó al norte de la raya del Biobío. La inmensa producción de plata que emanaba de Potosí dinamizó la economía del Cono Sur americano, generando una creciente demanda de cereales, sebos, cueros y cordobanes. Agotado el oro del sur, el fértil valle central era mirado ahora con interés. La economía indígena podía articularse con la del centro, mediante la provisión de ganado o textiles, sin necesidad de ocupar físicamente el territorio. Lo anterior habría permitido el surgimiento del espacio fronterizo y una creciente asimilación de hispanocriollos y mapuches.

La guerra, en adelante, se mantendrá intermitente, pero muy mitigada por la creciente interrelación cultural, étnica y económica entre las dos sociedades que coexisten al sur del Biobío. Si bien a lo ancho de la Araucanía la inseguridad es constante y hay varias sublevaciones significativas, como las de 1723 y 1769 , hacia mediados del siglo XVIII ya se ha instalado una nueva forma de relación, basada en el interés mutuo. El comercio de "conchavos", la inmigración espontánea y el mestizaje van originando tipos humanos y relaciones sociales propias del proceso de aculturación a que dan lugar las zonas fronterizas. El activo intercambio supera el nivel local y conecta a la Araucanía con las pampas transcordilleranas, dando lugar a circuitos comerciales que involucran al mundo mapuche con los hispanocriollos (León 1991). Se entreteje una complementariedad económica

1 Jorge Pinto apunta que la población de la Frontera pudo oscilar entre los 130.000 habitantes hacia 1720 y 220.000 en 1800, "una población no muy inferior a la del Valle Central" (Pinto 2000: 160). 
que tiene por actores a las haciendas fronterizas, los fuertes, los mercaderes, los caciques productores de ponchos y aquellos grupos que atraviesan la cordillera en busca de ganado. La magnitud y frecuencia del intercambio son difíciles de cuantificar, en razón de su carácter informal o, derechamente, clandestino. Incluía sal, vino, ponchos, y también mercancías de origen europeo, que se transaban a todo lo largo de la Frontera y por los boquetes cordilleranos ubicados de Curicó al sur². Es evidente, en todo caso, que este contacto interétnico generó una red de intereses y lealtades. Esta contribuye a explicar la supervivencia del espacio fronterizo a las reformas borbónicas, así como su resistencia posterior a los cambios que amenazaba la independencia.

La sociedad mapuche, que enfrentaba la penetración hispanocriolla, dividía el territorio en grandes extensiones, denominadas mapu o butalmapu. Se situaban entre los ríos Biobío y Bueno, más uno al norte y otro al sur de esos ríos. Siguiendo una dirección de mar a cordillera, se denominaban Lavquen-mapu, Lelvun-mapu, Inapire-mapu, Piremapu y Huilliche-mapu. Se subdividían a su vez en aillarehues, y estos en rehues. Los separaban límites naturales, como valles, ríos o cordilleras. Su unidad cultural se fundaba en la etnia y, sobre todo, en la lengua. El mapudungun se hablaba en toda la frontera e incluso en las pampas trasandinas (Zavala 2011). Más allá de la lengua y de un acervo cultural común, había entre los grupos indígenas profundas diferencias. El Walmapu o territorio mapuche, que incluía porciones de los actuales Chile y Argentina, albergaba a comunidades dispersas que habitaban un amplio espacio. Uno de los factores principales de su diferenciación, estribaba en la relación con la sociedad hispanocriolla y las autoridades del reino.

Los años de paz permitieron a diversas zonas de la Frontera alcanzar un cierto bienestar material. Así lo consignan los testimonios de los viajeros de los siglos XVIII y XIX. Mariman destaca que ninguno relata hambrunas o plagas, sino que al revés, comodidades alimenticias y de abrigo (Mariman 2006). Es evidente que lenta, pero inevitablemente, los mapuches habían abandonado su condición de recolectores, por una economía basada en la carne y los textiles, interdependiente del mundo español. Habían incorporado animales domésticos, trigo y otros cereales. Desarrollaron, asimismo, una industria del metal plata y el cuero; ambos elementos circularon como medios apreciados para el intercambio.

2 El visitador Juan de Ojeda, quien recorrió la frontera en 1793, por encargo del gobernador Ambrosio O’Higgins, comentaba que "el comercio activo de los pehuenches con los españoles consistía en sal, ponchos, plumajes, bateas, canastos, pellejos, añil, abalorios y alguna mercería” (Ojeda 1968: 50). 
Transcurridos tres siglos desde el inicio de la ocupación hispana, la Frontera había devenido un verdadero microcosmos, sobre la base de grupos autónomos, de conflictos, intercambios y alianzas. Los Parlamentos reducían las fricciones y facilitaban las comunicaciones y el comercio, por lo cual eran propiciados por las autoridades. Los circuitos comerciales interétnicos, a su vez, eran un instrumento idóneo para mantener la paz y favorecer los intereses imperiales.

En síntesis, en vísperas de 1810, al sur del Biobío se había estructurado un mundo fronterizo, caracterizado por la conjunción de dos pueblos originalmente muy diversos. A nivel étnico, económico y cultural, factor en que debe incluirse la lengua y la organización política, tres siglos en común dieron lugar a un complejo mestizaje, en diversos planos. Si bien convivían grupos con diversos grados de aculturación y se sucedían episodios violentos, la situación en general había evolucionado hacia una coexistencia pacífica. No había, tampoco, fuerzas suficientes para someter a los indígenas. La prioridad era mantener la calma en la Frontera, el intercambio y la seguridad de las costas. Lo anterior explica la reinstauración, a partir de 1817, de la política de Parlamentos y la mantención de la frontera virtual del Biobío.

Luego de la transitoria dislocación que produjo la década más violenta de la independencia (1813-1824), los circuitos y formas de relación coloniales se reconstituyeron. Mediante parlamentos y alianzas pudo proyectarse el mundo fronterizo tradicional hasta mediados del siglo. Por ley de 2 de julio de 1852, se crea la provincia de Arauco, con capital en Los Ángeles, la que debía administrarse como territorio fronterizo, "para el mejor gobierno de las fronteras, la eficaz protección de los indígenas, la promoción más pronta de su civilización y para arreglar contratos y relaciones de comercio con ellos". En 1869, se establecieron los departamentos de Angol, Lebu e Imperial, y se determinó considerarlos como territorios de colonización, sujetos a la autoridad ejecutiva establecida en Angol, convertida ahora en cabecera de la provincia. En esa época, la presión por incorporar las tierras indígenas impulsa la desintegración de la Frontera y su incorporación plena al Estado chileno.

\section{ARAUCO, MATRIZ RETÓRICA DE CHILE}

Las independencias nacionales hispanoamericanas, por su alcance continental y su carácter de fenómeno cultural, tuvieron diversas semejanzas. Una de las más significativas es el temprano rechazo al legado hispánico, acompañado, paralelamente, de la revalorización de lo indígena como fuente de legitimación. Esta condición, promovida 
de manera rápida y simultánea en los nuevos países, se manifiesta en símbolos, banderas y discursos, para luego desvanecerse, en la medida del ascenso del "panteón" nacional y del avance del liberalismo republicano.

Con los matices propios de su evolución histórica y situación geográfica, las referencias étnicas infiltran también la simbología republicana chilena. El empleo de elementos culturales mapuches -aún resignificados o semiolvidados- refleja de qué manera la Frontera contribuyó a plasmar nuestra identidad social y política. Su presencia se manifiesta, asimismo, en la toponimia y la conformación étnica del pueblo chileno. La examinaremos desde los primeros escritos e impresos de la Patria Vieja hasta su inusual pervivencia en los emblemas nacionales, como señal de su trascendencia en la configuración del Estado-nación chileno.

Aun cuando existían signos de descontento, en los años previos a 1810, para el grueso de la población y aun para los criollos más ilustrados, resultaba impensable la magnitud de los cambios que se vendrían. Formada la Primera Junta, con símbolos y gestos dramáticos se pretendió socavar las bases centenarias de la monarquía. Los discursos de igualdad remecían a una sociedad estratificada, que buscaba conciliar su estructura estamental con los nuevos valores republicanos. Los criollos que lideraron el proceso, quienes hasta hacía poco tiempo se consideraban los herederos orgullosos de los conquistadores, ahora renegaban de los años coloniales, calificándolos de "tres siglos de horror". Lo opuesto ocurrió con los indígenas, situados hasta entonces en la despreciada base de la pirámide social. Los talquinos, por ejemplo, que en 1796 habían pedido que su escudo de armas mostrase la derrota de Lautaro (Meza 1958), para 1812, movilizados por las nuevas ideas, convendrían en que dos "indios" representasen la república, como ocurrió en el primer escudo nacional.

Ocurrió así en toda América. La efímera república de Cartagena, en Colombia, reemplazó, en noviembre de 1811, los leones de España de su escudo por la imagen de una indígena ${ }^{3}$ (Lámina № 1). La ciudad de Salta fue más lejos, en el uso del 'Indio alegórico'. Al escudo que representaba a un español resistiendo el ataque de un indígena, el cabildo lo reemplazó en 1813 por el diseño exactamente contrario, de manera que el primero apareciera rindiéndose al segundo (Earle 2005). Monedas, banderas, estatuas, estampillas y topónimos, todo era un buen lugar para celebrar a los heroicos antepasados.

3 Así se lo describe: "Representa una india sentada a la sombra de una palma de coco, con su carcaj a la espalda, en la mano izquierda una cadena partida, en la mano derecha una granada abierta de la cual come un turpial" http://www.angelfire.com/realm/jolle/colombia/colombia-indep.htm (enero 2013). 


\section{Lámina No 1}

Armas del Estado de Cartagena de Indias, 1812

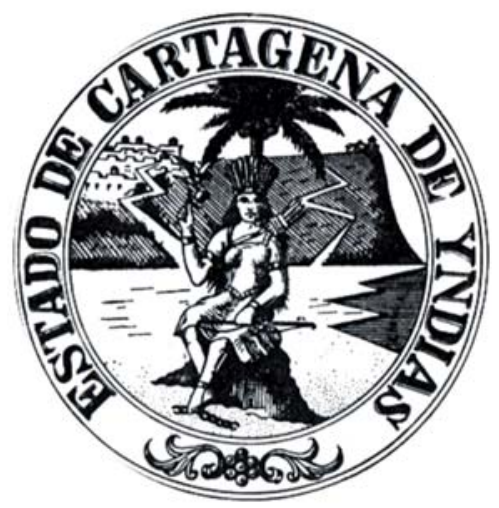

Fuente: Asociación de Historiadores Latinoamericanos y del Caribe ADHILAC 2013.

Chile no fue ajeno a esta tendencia. Los primeros buques fueron bautizados como Galvarino, Tucapel, Araucano o Lautaro. El último fue, además, el nombre de una importante logia revolucionaria (Eyzaguirre 1973) y, desde 1823, de una delegación y luego de un departamento de la provincia de Concepción. Es que, para entonces, los mapuches eran "nuestros padres", decía Ramón Freire, pues los chilenos éramos "hijos de Caupolicán, Colo-Colo y Lautaro”, según anunciaba en un brindis el general Francisco Calderón. Es "la idealización de la Araucanía", que bien ha descrito Simon Collier (1967). El republicanismo chileno -tal como se infiere del primer escudo nacional (1812)- "percibía en el pasado indígena su época clásica” y en los araucanos, por su espíritu libertario, el mito patriótico. En esta primera época, el adjetivo "araucano" llegó a ser un modo poético de decir "chileno" (Subercaseaux 2007).

El quiebre con la tradición hispana que representó la independencia, planteó el problema de identificar un pasado propio, alternativo, sobre el cual fundar la construcción nacional. Juan Egaña, en sus Cartas pehuenches, publicadas en 1819, imitando las Cartas persas, de Montesquieu, a través del supuesto diálogo de dos caciques de esa etnia, identificó el propósito de la independencia chilena con el de la Guerra de Arauco:

La actual revolución de Chile tiene el objeto más justo y necesario que pueda interesar a un pueblo: es el mismo por el cual nuestra nación sostuvo más de doscientos años de guerra; su libertad e independencia de la tiranía española (Egaña 2001: 34). 
La tarea no era fácil, sin embargo, pues la revolución era impulsada por los descendientes de los mismos conquistadores. "La revolución de 1810", dice Amunátegui, "debe considerarse en rigor una diferencia promovida por los españoles, i ventilada entre ellos" (Amunátegui 1876: 4). La lengua o la religión, al ser comunes a la región americana, no podían constituir un factor diferenciador adecuado para los países en formación. En el caso de Chile, tampoco podía serlo el territorio, discontinuado en la Araucanía y dividido en tres provincias, con identidades sociales y productivas diferentes. Así se explica que lo autóctono se impusiera en la primera época, a lo menos discursivamente. El supuesto esplendor de las sociedades precolombinas era el pasado mítico al cual asirse y su destrucción por los conquistadores, la justificación de su erradicación violenta. "El martirio atroz de la raza indígena de la América forma uno de los cuadros históricos más horripilantes de la barbarie humana", señala el mismo Amunátegui (1876: 5), pero sin dejar de notar, con la ambigüedad propia de una época posterior, la paradoja de que los verdugos de los indígenas, en el siglo XIX, eran los españoles americanos y no los españoles europeos. La invocación de Montezuma, Atahualpa, Caupolicán o Lautaro, concluye, "era una pura ilusión retórica".

La valoración del pasado indígena, en Chile, estuvo muy marcada por la lectura de La araucana, de Alonso de Ercilla, de manera que el énfasis se puso en el arrojo temerario y la tenaz resistencia mapuche, más que en una inexistente "Edad de Oro" o imperios indígenas, que en el país no hubo. El siglo XIX, dice Juan Mizón (2001:72), dio a Alonso de Ercilla "un reconocimiento pleno de historiador"; lo mismo que a sus continuadores e imitadores, como Pedro de Oña o Álvarez de Toledo. Como los textos de los cronistas, La araucana fue considerada una fuente principal de conocimiento histórico de la conquista de Chile. Surge así la tradición de épica guerrera y, con ella, el "mito" de la Guerra de Arauco, según Sergio Villalobos, que ha creado "una ilusión que se identifica con un destino nacional" (1995: 209), que se proyecta hasta el presente. En su época, marcó a la primera generación de republicanos y se plasma en himnos nacionales ${ }^{4}$, proclamas ${ }^{5}$, piezas de teatro ${ }^{6} \mathrm{y}$ en la prensa de la época. La última, especialmente profusa en nombres

4 La versión definitiva del Himno Nacional, encargada al poeta Eusebio Lillo, señala en su cuarta estrofa: "Con su sangre el altivo araucano,/ nos legó por herencia el valor;/ y no tiembla la espada en la mano/defendiendo de Chile el honor".

5 Bernardo O’Higgins exhortaba, en una proclama del 28 de enero de 1814, emitida en el Cuartel general de Concepción, a los habitantes de Penco a jurar que lucharían en nombre de "los manes del inmortal Lautaro, de Galvarino y de Caupolicán” por “vivir libres o morir con honor” (Academia Chilena de la Historia 1947: 36-37).

6 Introducción a la tragedia El triunfo de la naturaleza, de Bernardo de Vera y Pintado, representada el 20 de agosto de 1819 (Anrique 1899). 
indigenistas ${ }^{7}$, "relacionaba una expresión de la modernidad, como lo es la cultura escrita y la prensa, con el referente antiguo del indígena chileno, reactualizado por el patriotismo de la Independencia" (Silva 2008: 50).

Más que por su valor literario, que es innegable, era el contenido épico lo que se valoraba. Francisco A. Pinto cuenta en sus memorias:

Por primera vez leí en ese tiempo La Araucana de Ercilla, y nos reuníamos en corrillo para saborear su lectura. No era porque gustáramos de las bellezas de su poesía... sino por las heroicas hazañas de araucanos y españoles, que las considerábamos como propias (Casanueva 1998: 58).

Su lectura, alimentada por el romanticismo del siglo XIX, condiciona la mirada "científica" de los mapuches de Ignacio Domeyko o Claudio Gay; ambos naturalistas recorren la Araucanía con un ejemplar del libro de Ercilla en la mano. Según Mizón (2001: 72), antes de llegar a Chile, Gay "se impregna en la tradición épica chilena que lee en el puente de la fragata Adoum. Fue siempre un gran admirador de La Araucana y en sus comentarios y redacciones históricas tiene presente esta obra que le sirve de fuente". Con los años, aunque la mirada sobre los mapuches fue cambiando, anunciando la intervención del territorio, la opinión pública seguía influida por la tradición heroica.

Producida la consolidación de los Estados nacionales, hacia mediados de siglo, los héroes indígenas fueron reemplazados por los próceres de la independencia. Curiosamente, Chile habría sido la excepción: tras las campañas de ocupación de la Araucanía, en la década de 1880, los fuertes recién fundados reciben nombres indígenas e incluso uno es bautizado Lautaro. Para Rebecca Earle, sin embargo, el Estado chileno demostraba con ello "su soberanía, no sólo sobre el territorio de los mapuches, sino también sobre su pasado" (2005: 395).

La búsqueda de identificación con un mítico origen indigenista para la configuración de una nación, que permitiera diferenciarse del pasado colonial, planteaba dificultades. La identificación de un pasado "auténtico", atrapado en la era precolonial, genera el riesgo, denunciado por los estudios postcoloniales, de una "calcificación" de la cultura

7 Periódicos con nombres indígenas fueron, entre otros, el Monitor Araucano, émulo del Monitor Universal de Francia, principal diario de la revolución, fundado en 1789; El Araucano, la Ilustración Araucana, Correo de Arauco, Despertar Araucano o el Insurgente Araucano.

8 Entre los trabajos de Domeyko (1992) relacionados con la Araucanía, pueden mencionarse: Diario del viaje al país de los salvajes indios araucanos y Araucanía y sus habitantes (Ars Nova, Varsovia, 1992). (Cartes 2013). 
nacional (Earle 2005: 379). La república y el liberalismo que la inspiraba, en cambio, eran naturalmente progresistas, ilustrados y miraban a Europa y a Estados Unidos como sus referentes. La tensión entre la utopía de la sociedad indígena y el ascenso político y cultural a que aspiraban los republicanos se resolvió, al principio, de maneras extrañas. El periódico La Ilustración Araucana -nombre bastante decidor- apuntaba que Europa había esclavizado a "unos pueblos libres gobernados por un Congreso nacional, como la nación araucana" (Colección de Antiguos Periódicos Chilenos: 349); los "fieros republicanos de Arauco", los llama Simón Bolívar (1815). Según el periódico Observador Chileno, los araucanos seguían reglas democráticas infinitamente más avanzadas que las europeas de la época; "imaginaron la representación”, según El Mercurio de Chile (1823). Pero fue José Miguel Infante, sin duda, el más entusiasta, pues los declaró exitosos "federalistas", al punto que gracias a su organización habían podido resistir a los españoles, a diferencias de los "unitarios" incas y aztecas (Valdiviano Federal, 8 de julio de 1831 y 1832, citado en Collier 1964: 214).

Por estas consideraciones, junto al indigenismo abstracto, que invocaba el nombre de los antiguos guerreros, coexistió una visión evolutiva e integradora, que propiciaba la asimilación progresiva de los mapuches a la sociedad chilena. Camilo Henríquez, quien solía firmarse como Patricio Curiñacu, la expone en la Aurora de Chile (1982). Bajo el epígrafe "Civilización de los indios", sostiene, primero, que debe asegurárseles "que han de permanecer siempre libres, e independientes, gobernándose por sus propios Magistrados, sin disminuir un punto la dignidad de sus Caciques". Solo podía pedírseles una "confederación permanente y una cooperación activa en la necesidad". A través de la educación y el honor, agrega, "podremos obtener ventajas", pues "los indios están en estado de considerarse como una nación nueva, y por consiguiente fácil y dispuesta para ser ilustrada". Siendo la juventud la esperanza del Estado, concluye, bien dirigida viene a ser su gloria. Los indígenas debían ser educados fuera de su tierra, ya que "de retorno a su patria llevarán ideas exactas sobre la religión, la moral, la legislación, el comercio, la industria, la agricultura". Con estos conocimientos, "iluminarán" su país y permitirán que todos "nuestros compatriotas, Indios y Españoles, formen una sola familia, sujeta a unas mismas leyes, y a un solo Gobierno". El lugar adecuado, sostenía Henríquez, era la capital y, específicamente, el Instituto Nacional, donde un cuerpo de sabios velaría por sus progresos.

Como se aprecia, en la primera hora la política de la república hacia los indígenas promovió el respeto a sus territorios y liderazgos y la asimilación cultural, favoreciendo su incorporación a la "familia" chilena. El indigenismo chileno en tiempos de la independencia tiene rasgos que lo distinguen de lo ocurrido en otras naciones americanas. 
Fue intensamente influido, según hemos visto, por el mito épico de los guerreros de $L a$ araucana. La frontera indígena, además, aparecía separada, distante, de los espacios centrales desde donde se conducía, política e ideológicamente, el proceso emancipador. Según Bárbara Silva (2008: 52), el componente indígena tampoco era cuantitativamente tan significativo -lo que es discutible ${ }^{9}$ - y su belicosidad se hallaba reducida. De ahí que, a diferencia de otras naciones, no llegaría a cuestionar las bases de la construcción nacional de la elite; en otras palabras, "era posible utilizar este referente sin arriesgar la identidad de la eventual nación".

En Chile, cuando los mapuches se incorporaron masivamente a la lucha, esta se tornó violenta, haciendo tambalear el ánimo de invocarlos como símbolos de la patria. El ministro de Guerra, José Javier Bustamante, en su memoria de 1835, se refería a la participación de los mapuches junto a los bandos patriota y realista, a la luz de los partes de Bulnes. "Esta división ha sido de consecuencias espantosas, no sólo para ellos mismos, sino también para nosotros. Desde esa época nos han hecho una guerra destructora, dirigidos las más de las veces por caudillos enemigos de nuestra causa" (Mizón 2001: 84). Esta incomprensible 'traición', sumada al discurso de la barbarie y a la consolidación del panteón republicano, determinará su reemplazo por los arquetipos nacionales: los próceres de la independencia y, a partir de la Guerra contra la Confederación Peru-Boliviana (1836-1839), por el "roto chileno" (Cid 2011). Establecida la República, la mirada ya no se fijará en "el pretérito heroico ni en la utopía igualitaria; el modelo al que se aspiró fue el europeo" (Gallardo 2001: 131). En el imaginario popular, en todo caso, la imagen estereotipada de los guerreros araucanos sobrevivirá hasta el presente (Casanova 1996). Se refleja, con ello, la identidad ambigua -casi dual- del país.

\section{LA ETNICIDAD DE LOS SÍMBOLOS PATRIOS}

La búsqueda de legitimación del separatismo de España condujo, según hemos visto, a una revalorización del mundo precolombino y de lo indígena. En Chile, el influjo de La araucana y la imagen heroica de la secular Guerra de Arauco llevó a enfatizar la resistencia mapuche, así como la cosmología y lo telúrico de la región del sur. Como en el resto de América, esta mistificación, de corte más ideológico que de cercanía real al mundo indígena, se fue diluyendo con los años. Debe reconocerse, no obstante, aun concediendo la polisemia propia de banderas o escudos, que elementos de aquel mundo subsisten hasta el presente en los emblemas patrios. Se refleja, así, la gravitación de la

9 La población de la Araucanía, en la época, era cercana a los 200.000 habitantes, según Jorge Pinto y Tomás Guevara, no muy inferior a la del valle central. 
sociedad mapuche en la etapa de organización nacional y el afán de integrarla simbólicamente, junto con su territorio y habitantes, a la república que surgía. Esta no se concebía, en efecto, sin la participación o la inclusión de los habitantes del sur: es lo que manifiestan los símbolos patrios. Aunque en las décadas siguientes, la Frontera fue relegada a la posición de región periférica, un problema pendiente de la República, sus símbolos muestran de qué manera lo indígena ideológicamente fue, y sutilmente sigue siendo, parte de la nación.

La trayectoria de los escudos patrios, en primer término, da cuenta, a pesar de los cambios, de la pervivencia de la matriz indígena de nuestra nacionalidad. El primer escudo fue presentado con ocasión de la celebración del segundo aniversario de la Junta de septiembre, organizada con gran pompa, en la Casa de Moneda, por José Miguel Carrera, para el 30 de septiembre de 1812. Iluminaciones generales, salvas y un tedeum dieron realce a la ocasión. En la animada fiesta que reunió a lo más granado de la sociedad patriota, relata el cronista Melchor Martínez, brillaban las damas chilenas, pero

en especial se llevaron la atención dos de ellas que para realzar sobre todas su patriotismo asistieron vestidas con traje de "indias bárbaras", lo que era digno de advertirse, añade, considerando que la una era natural de la Corte de Madrid y había sido dama de la Reina... y la otra era esposa de un madrileño, sin cuya anuencia no debía proceder de ese modo (1848: 150).

Irrumpía, de esta forma, el indigenismo romántico en medio de la sociedad criolla, como signo de los nuevos tiempos.

En la ocasión, hizo su aparición también el escudo. "En lo más elevado de la portada principal [relata el mismo cronista Martínez], figuraba un alto monte o cordillera, sobre cuya eminencia aparecían muchos rayos de luz" (Martínez 1848: 150) y una inscripción alusiva a la aurora de la libertad de Chile. Bajo esta había un lienzo con un escudo ovalado, en que figuraba una robusta columna, un globo, con una lanza y una palma cruzada, sobre las cuales se descubría una radiante estrella. "A la siniestra de la columna estaba un gallardo joven vestido de indio, y a la diestra una hermosa mujer con el mismo traje" (Martínez 1848: 150). Aunque no hay representaciones contemporáneas del emblema, esta descripción es la que siguen la mayoría de los estudiosos de los símbolos patrios, a partir de Vidal Gormaz (1883) y su obra sobre Los emblemas nacionales (Lámina № 2). Sobre el autor del escudo no hay mayores datos, aunque las pesquisas inconclusas de José Miguel Barros (1997) lo atribuyen al trujillano Isidro Antonio de Castro. 


\section{Lámina No 2}

Escudo de la Patria Vieja, Anónimo, Chile, Siglo XX, Óleo sobre tela.

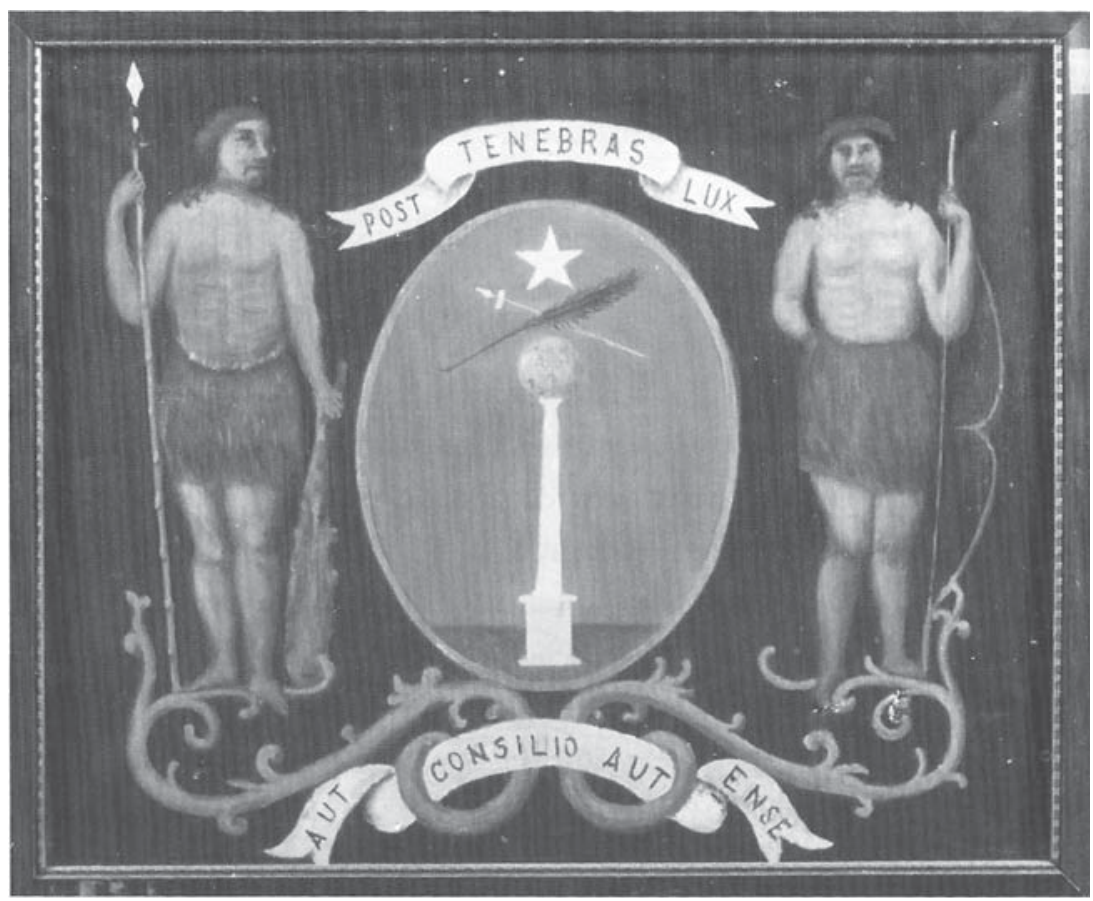

Fuente: Comisión Bicentenario 2010.

El blasón con la pareja de mapuches reflejó el indigenismo de la primera hora. En los escudos patrios, según Gastón Soublette (1984: 105), el pueblo araucano ha sido incluido con "la clara intención de definir el nuevo orden de Chile como basado en el valor y nobleza de Arauco, cuya sangre corre por nuestras venas" y no solo por razones estratégicas.

En la Patria Vieja, para los líderes capitalinos, el referente mapuche distaba de ser real, ya que aunque sobrevivía en regiones del sur, la realidad cotidiana era la de un país mestizo. La elite criolla no se sentía realmente heredera del mundo indígena, de manera que, en la práctica, el uso de estos referentes no amenazaba la estabilidad del proyecto de construcción nacional. Por lo demás, así ocurrió en muchas regiones de América, donde la iconografía indígena fue desapareciendo en las décadas siguientes a la independencia. En Colombia, por ejemplo, la "princesa india" que había simbolizado la libertad y la re- 
pública fue reemplazada, en 1821, por un busto femenino cubierto por una toga. Para entonces, una mujer indígena ya únicamente podía representarse a sí misma, dice Rebbeca Earle y jamás a la república $(2005: 394)^{10}$.

Declarada ya la independencia y luego de la victoria de Maipú, que la afianzó en Chile central, el gobierno de Bernardo O’Higgins se ocupó de crear un nuevo escudo patrio. El Senado conservador, por acuerdo del 23 de septiembre de 1819, refrendado por el Director Supremo, fijó el nuevo emblema. Este conservó la columna y la estrella, pero suprimió los lemas latinos, la palma y la lanza cruzadas y las dos figuras indígenas. Por orden del gobierno, el escultor chileno Ignacio Andía y Varela grabó este escudo en madera. Este era sostenido, según la descripción de Benjamín Vicuña Mackenna, por un "bizarro bárbaro americano", a caballo de un caimán, que simbolizaba a América y que devoraba al león de Castilla (Vicuña Mackenna 1931, citado en Soublette 1984: 102). Es el escudo que figura en el retrato de Bernardo O'Higgins, pintado en 1821, por el mulato José Gil de Castro. La columna, según Soublette (1984: 105), representa el Árbol de la libertad, asociándolo así al "sentido libertario del pueblo araucano", de la misma forma como el indígena, en la base del símbolo, adquiere el carácter de fundamento (Lámina No 3). Significaciones que, en nuestro concepto, resultan forzadas, atendida la recurrencia de la imagen del indígena y la cornucopia en la heráldica americana y el sentido clásico de la columna -de orden dórico, según el decreto constitutivo-, alegoría ampliamente utilizada en las representaciones republicanas francesas (Zaldívar y Sánchez 2010: 61).

\section{Lámina No 3}

Don Bernardo O’Higgins, Director Supremo, por José Gil de Castro (detalle)

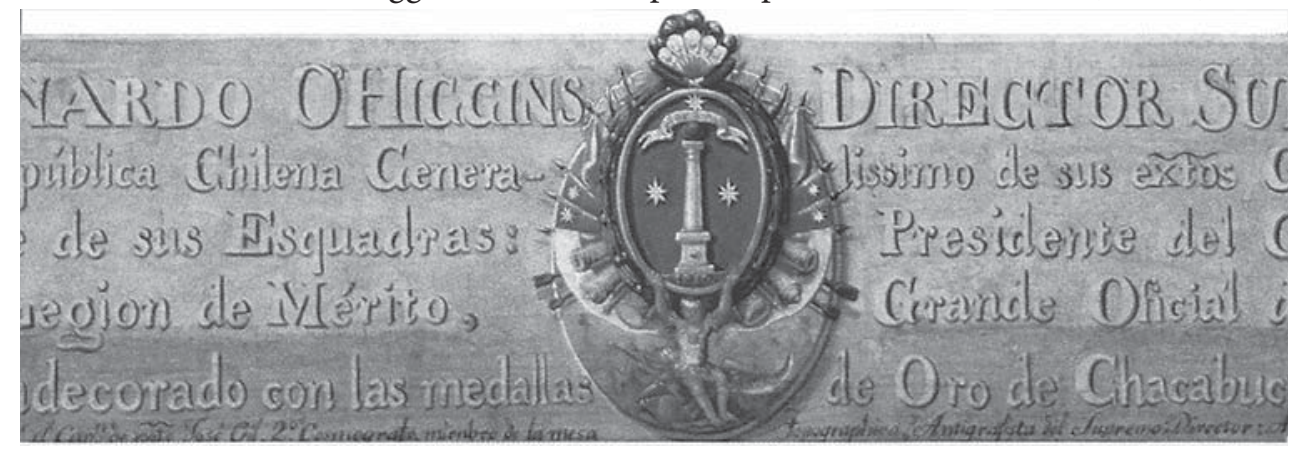

Fuente: Colección Museo Nacional de Bellas Artes.

10 Para la segunda mitad del siglo XIX, informa, las imágenes de indígenas habían sido virtualmente erradicadas de monedas, estampillas o símbolos patrios. Ya no podían representar al Estado. Solo se repondrán avanzado el siglo XX, como expresión, en general, de un indigenismo oficial (Earle 2005: 406-407 y 410-11). 
Consolidada la república, pareció oportuno avanzar hacia la instauración de un escudo más definitivo, que reflejara la anhelada grandeza del país. Con el triunfo de las fuerzas conservadoras en Lircay, comenzaba a instalarse el Estado "fuerte, centralizador", a que aspiraba el grupo pelucón, en la conocida expresión de Diego Portales. No servía, a este propósito, un escudo con tres estrellas, que representaban a las provincias históricas de Santiago, Concepción o Coquimbo. En adelante, una única estrella bastaría para representar el triunfo del unitarismo sobre las aspiraciones federalistas y provinciales. Afirmando, pues, "el Gobierno, que no debiéndose tolerar por más tiempo ese escudo insignificante y abortivo", resultaba necesario sancionar uno más adecuado, según señala el mensaje del proyecto de ley de junio de 1834, que firmaran el presidente Prieto y el ministro Tocornal, se convocó a un concurso público para el nuevo escudo nacional. El diseño ganador, propuesto por el artista Carlos C. Wood Taylor, es el escudo actual (Lámina $\mathrm{N}^{\circ} 4$ ), con ligeras modificaciones. Fue aprobado por el Congreso Nacional el $24 \mathrm{de}$ junio de 1834 (Amunátegui 1910).

\section{Lámina No 4}

Escudo Nacional de Chile, adoptado en 1834

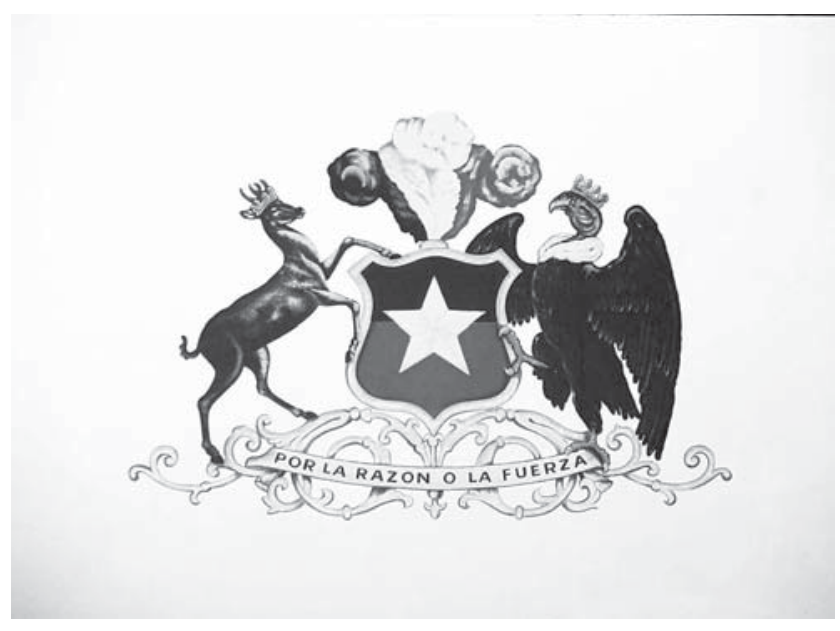

Fuente: Fotos, dibujos, cultura y geografía 2013.

El mensaje del proyecto de ley, redactado por José Ignacio Zenteno, refiere en tres ocasiones a Arauco y los indígenas, mostrando con ello la importancia simbólica que todavía conservaba, en 1834, la región y sus habitantes. Señalaba, en efecto, en parte, la descripción del emblema: 
En él observará el Congreso un campo de dos esmaltes, cuyos bien conocidos atributos cuadran perfectamente con la naturaleza del país y el carácter de sus habitantes. Alude también al antiguo distrito colonial de Chile y al territorio de Arauco, importante adquisición de la República. La estrella de plata es el blasón que nuestros aborígenes ostentaron siempre en sus pendones y el mismo que presenta ese caro pabellón, a cuya sombra se ha ceñido la patria de tantos y tan gloriosos laureles; puede también referirse a nuestra posición geográfica, la más austral del orbe conocido. La insignia que se ve por timbre es la que adorna el sombrero del Presidente de la República, como característica de su dignidad suprema.

Los soportes representan un huemul y un cóndor, éste, el ave más fuerte animosa y corpulenta que puebla nuestros aires, y aquél, el cuadrúpedo más raro y singular de nuestras sierras, de que no hay noticia que no habite otra región del globo y de cuya piel, notable por su elasticidad y resistencia, hacen nuestros valientes naturales sus coseletes y botas de guerra... (Amunátegui 1910: 589) ${ }^{11}$.

Es revelador conocer la significación que dio al Escudo Nacional el propio presidente que lo propuso al Congreso, a pesar de que, con los años, las interpretaciones puedan variar o, simplemente, caer en el olvido. Observamos que se divide en dos campos, que representan al Chile tradicional - "el antiguo distrito colonial" - y a la región de Arauco, habitada por "los indómitos y libres araucanos, vecinos y compatriotas" del Reino de Chile, al decir de Simón Bolívar, cuyo territorio, en todo caso, aclara el mensaje, era ya una "adquisición” republicana. Los esmaltes azul y rojo, en su proximidad, significarían la polaridad espíritu-vida, homologadas, "en la integración de dos naciones que dieron origen a la sociedad chilena: el Chile colonial y la nación araucana” (Soublette 1984: 114).

La estrella, por su parte, es uno de los elementos más ambivalentes de la heráldica. Se ha dicho, en efecto, que evoca el carácter unitario del Estado, la tradición católica mariana como Stella Maris ${ }^{12}$, un símbolo de la Ilustración ${ }^{13}$, o la estrella araucana, Guñelfe, esto es, el planeta Venus, la estrella de la mañana. Para el escudo de 1834, no obstante, no existe ambigüedad: representa, según el mensaje, "el blasón que nuestros aborígenes ostentaron siempre en sus pendones". A pesar de que, como elemento mágico o simbólico, puede adscribirse a muchas tradiciones, la estrella ocupa un rol indudable en la cosmogo-

11 El destacado corresponde al autor.

12 La estrella de Arauco, como lucero del alba, corresponde a uno de los apelativos de la Virgen María como Stella Matutina. Así lo aclararon las hermanas Pineda, quienes confeccionaron el primer ejemplar de la bandera utilizada en Concepción para la fiesta de la Virgen del Carmen, en noviembre de 1817 (Soublette 1984: 97).

13 La estrella puede también representar las "luces", es decir, "el triunfo de la razón frente al oscurantismo de los sentidos y las concepciones míticas del poder y del mundo” (Zaldívar y Sánchez 2009: 96). 
nía mapuche. Según declaró el mismo O’Higgins, a propósito de la bandera, la estrella de la bandera era la estrella de Arauco. Así se entendía en la época, incluso en celebraciones públicas. En la iconografía mapuche, Wünelfe, castellanizado guñelve, es el lucero o Venus, que se representa con una estrella octogonal o una cruz foliada. Figura de esta forma en testimonios del siglo XVIII y textos posteriores, como el del escritor y diplomático francés César Famin (1840: 14); es la imagen que reproduce la conocida representación del cacique Lautaro por el pintor Fray Pedro Subercaseaux. Aunque la estrella adoptada finalmente fue la de cinco puntas, el diseño del guñelve se insertó inicialmente, en la bandera, como un asterisco de ocho brazos inserto en el centro de la estrella, "representando la combinación de las tradiciones europea e indígena". En definitiva, la estrella araucana, como el sol inca que San Martín incorporó a las banderas argentina y peruana, son símbolos que permanecen hasta hoy, aunque, como en estos casos, su significación se haya desdibujado con el tiempo. Los proyectos nacionales, decía Ernest Renán, requieren de memorias comunes, pero también de olvidos.

En tercer término, los animales elegidos también refieren a la tradición aborigen. El cóndor, aun antes de la Conquista, "los naturales de Arauco se complacían en tomarlo como símbolo" (Amunátegui 1910: 591). El huemul, por su parte, escaso y venerado por el elogio que de él hiciera el abate Juan Ignacio Molina, era también notable -dice el mensaje presidencial- por el uso que daban a su piel los indígenas.

Finalmente, aunque no lo significa el mensaje, el "plumaje tricolor de azul, blanco y encarnado", que tiene por timbre el escudo, igual ha sido relacionado a la épica de $L a$ araucana. Unos conocidos versos, referidos al cacique Talcahuano, hacen alusión a los colores patrios ${ }^{14}$. Dieron "sin duda la base", afirma Soublette (1984: 72), "para la composición del pabellón" conforme a la tendencia indigenista. Nuevamente, sin embargo, lo anterior parece a lo menos ambiguo, pues son asimismo los colores de la Revolución francesa y de la bandera estadounidense, de modo que resulta imposible vincular el origen de los colores patrios a una única influencia.

La bandera nacional de Chile también da cuenta de la influencia de lo indígena. La actual fue adoptada oficialmente el 18 de octubre de 1817. La estrella pentagonal tiene muchas interpretaciones, que ya hemos referido. Sobre los colores, además de la alusión a La araucana, se han insinuado muchas otras, relativas a valores, como la justicia o la razón, o bien de orden telúrico, asociando el azul a los cielos y el océano Pacífico y el blanco

14 "Pasó tras éste luego Talcaguano, [...]/ cubierto de altas plumas, muy lozano,/ siguiéndole su gente de pelea,/ por los pechos al sesgo atravesadas/ bandas azules, blancas y encarnadas” (Canto XXI). 
a las cumbres nevadas de los Andes. En cuanto al rojo, comenzó simbolizando la sangre araucana y luego también la de los mártires de la independencia.

La bandera original fue presentada oficialmente durante la ceremonia de juramento de la independencia, el 12 de febrero de 1818 (Lámina No 5). La estrella, ligeramente inclinada hacia la zona del mástil, tenía la especial característica de portar, en su centro, un asterisco de ocho brazos zurcido con perlas de pequeño tamaño. Correspondería a guñelve, la estrella de la mañana mapuche a que hemos aludido. Sintetiza, de esta forma, la tradición pitagórica europea, mediante la estrella de ocho brazos pentagonal y la tradición indígena ${ }^{15}$. Estos diseños, que incluían un escudo bordado, se simplificaron más tarde, probablemente por la dificultad en la construcción de la bandera. Recién en 1854 se fijaron las proporciones de los colores y, en 1912, el diámetro de la estrella y la precedencia de los colores ${ }^{16}$.

\section{Lámina No 5}

Bandera Nacional, adoptada en 1818

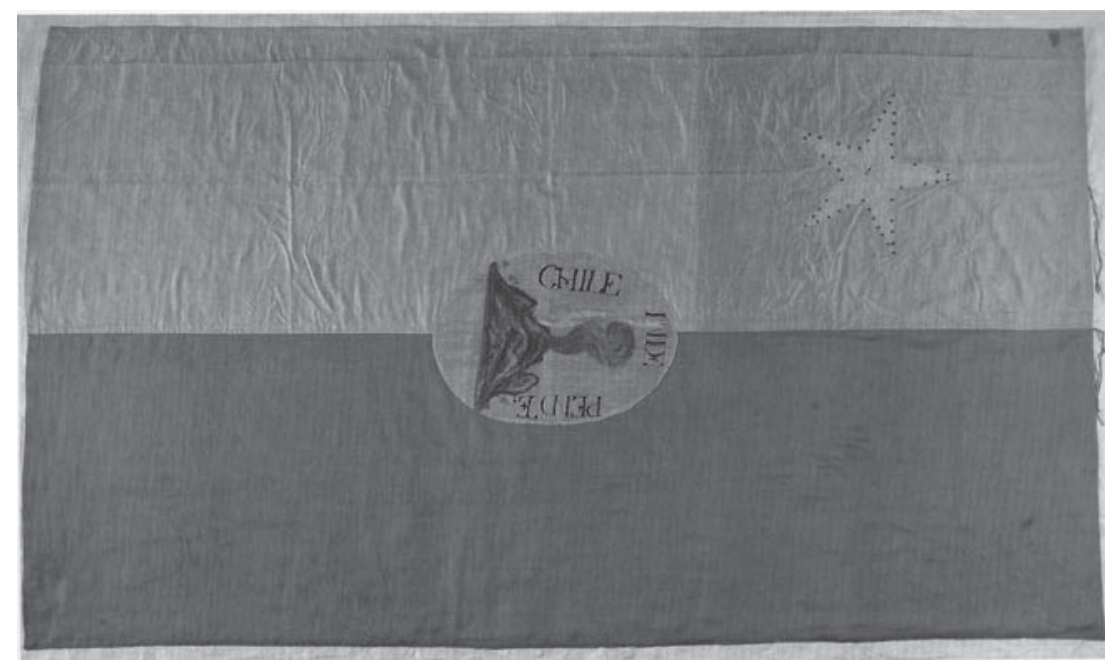

Fuente: Comisión Bicentenario 2010.

15 Esta bandera fue hurtada por un comando del Frente Patriótico Manuel Rodríguez, en 1980, y recién recuperada en 2003. Sometida a una cuidadosa restauración, con ocasión del Bicentenario, hoy se custodia en el Museo Histórico Nacional (Comisión Bicentenario 2010).

16 Disposiciones luego refundidas en el Decreto $\mathrm{N}^{\circ} 1.534$, del 12 de diciembre de 1967, del Ministerio del Interior. 
El escudo bordado (Lámina № 6) muestra a un costado el árbol de la libertad, un rehue con sus respectivas banderas de nguillatun, según interpreta Soublette, forzando los conceptos, a partir del indigenismo que atribuye a O'Higgins. En el reverso figura un volcán en erupción, con la expresión abreviada "Chile independiente". Es una figura muy interesante, que puede representar la cordillera andina, tras la cual amanecía, haciendo honor al lema del primer escudo carrerino, post tenebras lux, presentado en la fiesta de 30 de septiembre de 1812. Lo más probable, sin embargo, es que el volcán haya sido incorporado por Bernardo O'Higgins, urgido por desterrar la figura del rey de monedas y emblemas, y motivado, a la vez, por la imponente presencia de los volcanes de su región natal ${ }^{17}$ (Lámina $\mathrm{N}^{\circ} 7$ ).

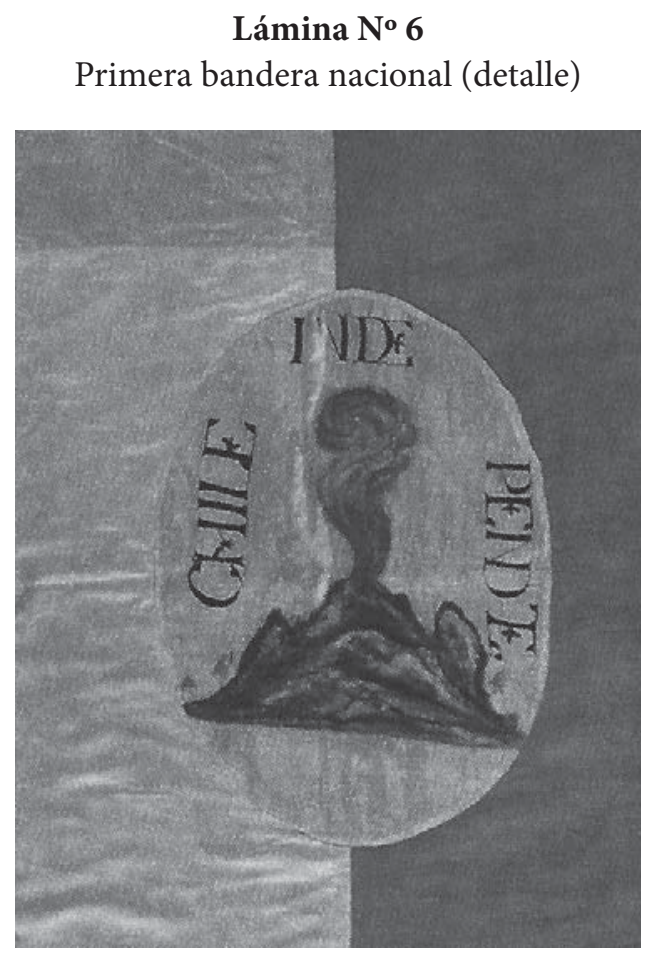

Fuente: Comisión Bicentenario 2010.

17 El volcanismo es un fenómeno característico de los Andes en Biobío. Entre las cumbres que corresponden a conos volcánicos pueden mencionarse los Nevados de Chillán, los volcanes Callaqui, Chillán, Antuco y Copahue. Todos, salvo el Antuco, de poco más de 3.000 metros de altura y visibles en los frecuentes viajes que el Libertador hacía, en la primera década del siglo XIX, entre su casa de Chillán y su hacienda Las Canteras. 


\section{Lámina No 7}

Croquis de la Isla de la Laja, 1757

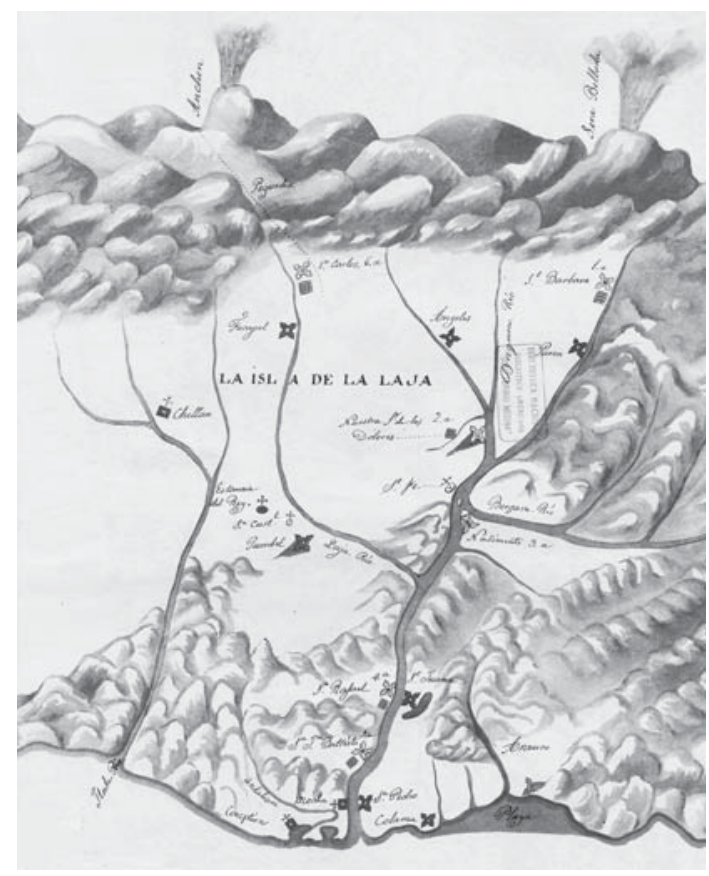

Fuente: Colección Sala Medina, Biblioteca Nacional.

Por Orden del Director Supremo, que se hallaba a la sazón en el sitio de Talcahuano, Hilarión de la Quintana promulgó un bando, el 9 de junio de 1817, relativo a la nueva moneda de plata que se fundiría. El sello del gobierno reemplazaría al busto de Fernando VII y, en el reverso, decía el decreto, "presentará un volcán y encima una corona de laurel, en cuyo centro se pondrá el valor" (Medina 1902). Desde el mismo campamento, dispuso O’Higgins la creación de la Legión del Mérito de Chile, cuyas medallas, de oro labrado y esmaltado en Francia, tenían también en su anverso la figura del volcán (Eyzaguirre 1933). Su propio retrato, confeccionado por Gil de Castro, en 1821, contenía en el fondo del escudo, situado en la base, la imagen de cuatro volcanes en erupción. Según la mitología mapuche, explica Soublette, corresponden a cuatro pillanes o espíritus señores de la guerra $^{18}$. De manera que, en la bandera de la jura, el volcán en erupción simbolizaría la

18 Según Soublette, "estos aparecen en ciertas invocaciones bajo el nombre de meli hueichán huentru ("cuatro valientes guerreros") o meli hueichafe huentru ("cuatro hombres luchadores"). Estos dioses constituyen un 
fuerza telúrica de la rebelión patriota, emanada de la herencia araucana representada en el pillán de la guerra.

\section{CONCLUSIÓN}

Con todos estos antecedentes, no puede sino concluirse, con Luis Mizón (2001: 74), que en la concepción simbólica de la bandera, lo que es extensible también al escudo, se habría producido "un verdadero mestizaje de elementos indígenas y occidentales religiosos y esotéricos". Aunque es difícil desprender significaciones unívocas en una cuestión tan polisémica y evolutiva, resulta evidente que los elementos indígenas, ya sea en monedas, escudos y banderas, fueron fundamentales para la incorporación simbólica de la Araucanía a la República. Si bien con el tiempo se ha reducido su significación, no por ello, según hemos demostrado, han perdido presencia.

En los debates actuales sobre la constitución de un Estado plurinacional, o sobre la pertenencia política o cultural del mundo mapuche al Estado chileno, las discusiones de comienzos de la república, en el campo simbólico o estético, pueden revisitarse con provecho. Nos recuerdan la importancia que tuvo la cuestión étnica en los debates sobre la configuración del país naciente, el cual no se concebía sin la inclusión de sus habitantes aborígenes. Los símbolos así lo reflejan. Aunque con los años perdieron su significación, debe esta recuperarse a fin de valorar la importancia de la matriz indígena en la conformación del país y la contribución que implica su presencia a la identidad múltiple de Chile.

\section{REFERENCIAS}

1. Academia Chilena de la Historia. 1947. Archivo de don Bernardo O'Higgins. Santiago: Editorial Nascimento.

2. Amunátegui, Miguel Luis. 1876. La crónica de 1810. Santiago: Imprenta de la República.

3. ----. 1910. Los precursores de la Independencia. Santiago: Imprenta, Litografía y Encuadernación Barcelona.

cuaternario celestial menor frente al ñidol o supremo. Su simbolización por medio de volcanes en erupción proviene de la mitología de los volcanes" (1984: 107). 
4. Asociación de Historiadores Latinoamericanos y del Caribe ADHILAC 2013. Armas del Estado de Cartagena de Indias, 1812. Consultado el 20 de mayo de 2013 (http://adhilac. com.ar/?p=1204)

5. Anrique R., Nicolás. 1899. Ensayo de una bibliografía dramática chilena. Santiago: Imprenta Cervantes.

6. Aurora de Chile, Tomo I, No 12 , Jueves 30 de abril de 1812.

7. Barros, José Miguel. 1997. "Acerca del primer escudo de Chile." Boletín de la Academia Chilena de la Historia 106: 26-30.

8. Cartes, Armando. 2013. Viajeros en tierras mapuches. 2013. Tomé: Editorial al Aire Libro.

9. Casanova, Holdenis. 1996. "La Araucanía colonial: discursos, imágenes y estereotipos (1500-1800)." Pp. 41-82, en Del discurso colonial al proindigenismo. Ensayos de historia latinoamericana, editado por Jorge Pinto. Temuco: Ediciones de la Universidad de la Frontera.

10. Casanueva, Fernando. 1998. "Indios malos en tierras buenas. Visión y concepción del mapuche según las elites chilenas del siglo XIX." Pp. 291-327 en Modernización, inmigración y mundo indígena. Chile y la Araucanía en el siglo XIX, editado por Jorge Pinto. Temuco: Ediciones Universidad de la Frontera.

11. Cid, Gabriel. 2011. La Guerra contra la Confederación. Imaginario nacionalista y memoria colectiva en el siglo XIX chileno. Santiago: Ediciones Universidad Diego Portales.

12. Colección de Antiguos Periódicos Chilenos, 1813-1817. 1954. Tomo II. Santiago de Chile: Imprenta Cultura.

13. Colección de Historiadores y de Documentos relativos a la Independencia de Chile, tomo XLI.

14. Collier, Simon. 1967. Ideas and politics of Chilean independence 1808-1833. Cambridge: Cambridge at the University Press.

15. Comisión Bicentenario. 2010. Doscientos años, una bandera. Proceso de restauración Bandera de la Jura de la Independencia. Santiago: Comisión Bicentenario.

16. Domeyko, Ignacio. 1992. Araucanía y sus habitantes. Varsovia: Ars Nova. 
17. Earle, Rebecca. 2005. "Sobre héroes y tumbas: National Symbols in Nineteenth-Century Spanish America." Hispanic American Historical Review 85 (3): 375-416.

18. Egaña, Juan. 2001. Cartas pehuenches, o, Correspondencia de dos indios naturales del PireMapu, ó sea la cuarta tetrarquía en los Andes, el uno residente en Santiago, y el otro en las cordilleras pehuenches. Santiago: Ediciones de la Universidad de Chile.

19. Eyzaguirre, Jaime. 1973. La Logia Lautarina y otros estudios sobre la independencia. Santiago: Editorial Francisco de Aguirre.

20. ----. 1933. “La Orden al Mérito de Chile.” Boletín de la Academia Chilena de la Historia 2 (1): $87-117$.

21. Famin, César. 1840. Chili, Paraguay, Uruguay, Buenos-Ayres. París: Firmin Didot Fréres ed.

22. Fotos, dibujos, cultura y geografía. 2013. Fotosdeculturas.blogspot.com

23. Gallardo P., Victoria. 2001. "Héroes indómitos, bárbaros y ciudadanos chilenos: el discurso sobre el indio en la construcción de la identidad nacional." Revista de Historia Indígena 5: 119-34.

24. León, Leonardo. 1991. Maloqueros y conchavadores en Araucanía y las Pampas 17001800. Temuco: Ediciones Universidad de la Frontera.

25. Martínez, Fray Melchor. 1848. Memoria histórica sobre la Revolución de Chile desde el cautiverio de Fernando VII hasta 1814. Valparaíso: Imprenta Europea.

26. Medina, José Toribio. 1902. Monedas y medallas chilenas. Santiago: Impreso y grabado en casa del autor.

27. Meza, Néstor. 1958. La conciencia política chilena durante la monarquía. Santiago: Universidad de Chile.

28. Mizón, Luis. 2001. Claudio Gay y la formación de la identidad cultural chilena. Santiago: Editorial Universitaria.

29. Ojeda, Juan de. 1968. “Descripción de la Frontera de Chile." Revista Chilena de Historia y Geografía 136: 38-72.

30. Sesiones de los Cuerpos Legislativos de Chile, tomos I, II y XVI. 
31. Silva A., Bárbara. 2008. Identidad y nación entre dos siglos. Santiago: Lom Ediciones.

32. Soublette, Gastón. 1984. La estrella de Chile. Valparaíso: Ediciones Universitarias de Valparaíso.

33. Subercaseaux, Bernardo. 2007. Historia de las ideas y la cultura en Chile. Santiago: Editorial Universitaria.

34. Vicuña Mackenna, Benjamín. 1868. La Guerra a Muerte. Santiago: Imprenta Nacional.

35. ----. 1931. Algunos proverbios, refranes, motes y dichos nacionales. Santiago: Talleres Gráficos Salesianos.

36. Vidal, Francisco. 1883. Anales de la Universidad de Chile $\mathrm{N}^{\circ} 64$.

37. Villalobos, Sergio. 1989. Los pehuenches en la vida fronteriza. Santiago: Ediciones Universidad Católica de Chile.

38. ----. 1995. Vida fronteriza en la Araucanía. Santiago: Editorial Andrés Bello.

39. Zaldívar, Trinidad y Macarena Sánchez. 2010. "Símbolos, emblemas y ritos en la construcción de la nación. La fiesta cívica republicana: Chile 1810-1830.” Pp. 73-116 en Nación y nacionalismo en Chile, siglo XIX, vol. 2, editado por Gabriel Cid y Alejandro San Francisco. Santiago: Centro de Estudios Bicentenario.

40. Zavala, José Manuel. 2011. Los mapuches del siglo XVIII. Temuco: Ediciones UC Temuco. 